\title{
Modeling the spatio-temporal dynamics of malaria parasite population genetics
}

\author{
Edward Wenger*, Joshua Proctor, Philip Eckhoff \\ From Challanges in malaria research: Core science and innovation \\ Oxford, UK. 22-24 September 2014
}

\begin{abstract}
A model of malaria transmission dynamics is presented that tracks the genetic barcodes of individual Plasmodium falciparum infections using seasonally-driven effective reproduction rates for clonal propagation, external importation, and the outcrossing of strains both within and between infections. We explore quantitatively the relationship between transmission intensity and genetic observations, for example the repeated observation of identical strains and their persistence across successive transmission seasons. Extending to a spatially connected network of human and parasite populations, we model the sensitivity of genetic sequencing to identify the relative contributions of local hotspots versus re-importation in sustaining transmission in pre-elimination settings. Finally, we model the effects of local transmission intensity and anti-malarial drug pressure on the population-level genetic signatures of emerging drug resistance.
\end{abstract}

Published: 22 September 2014

doi:10.1186/1475-2875-13-S1-017

Cite this article as: Wenger et al: Modeling the spatio-temporal

dynamics of malaria parasite population genetics. Malaria Journal 2014

13(Suppl 1):017.

Institute for Disease Modeling, Bellevue, WA, USA

Submit your next manuscript to BioMed Central and take full advantage of:

- Convenient online submission

- Thorough peer review

- No space constraints or color figure charges

- Immediate publication on acceptance

- Inclusion in PubMed, CAS, Scopus and Google Scholar

- Research which is freely available for redistribution 